\title{
Effect of Bleeding on the Modori-phenomenon and Possible Existence of Some Modori-inhibitor(s) in Serum
}

\author{
Haruhiko Toyohara, ${ }^{* 1}$ Kazuo Sasaki, ${ }^{* 1}$ Masato Kinoshita,*1 \\ and Yutaka Shimizu*1
}

(Received December 15, 1989)

\begin{abstract}
Effect of bleeding on the modori-phenomenon of gels prepared from rainbow trout muscle in association with death condition and freshness was examined. It was suggested that bleeding might promote the modori-phenomenon irrespective of the death condition. Additionally, the modoriproperty changed according to freshness. However, the relationship between the post mortem $\mathrm{pH}$ and the modori-property was not clearly demonstrated.

Promotion of the modori-phenomenon by bleeding suggested the existence of some inhibitor(s) for the modori-phenomenon in blood. Actually, the addition of the serum fraction of rainbow trout blood suppressed the modri-phenomenon as well as the breakdown of myosin heavy chain.
\end{abstract}

Recent work in our laboratory have suggested that the modori-phenomenon (thermal gel degradation particularly occurs around $60^{\circ} \mathrm{C}$ ) is caused by a group of newly found endogenous serine proteinases having strong degrading action on myosin heavy chain. ${ }^{1-4)}$ Additionally, it is also suggested that the modori-phenomenon shows remarkable species-specificity. ${ }^{\text {s) }}$ It was also reported that the modori-property depends on various biological factors including death condition, ${ }^{\text {a) }}$ freshness, ${ }^{\text {()) }}$ size, ${ }^{7)}$ age, ${ }^{7)}$ season, ${ }^{7,8)}$ and nutritional condition*2 even in the same species.

On the other hand, we found that bleeding may also affect the degree of the modori-phenomenon through a series of the study on the modoriphenomenon. Therefore, the effect of bleeding in association with death condition and freshness was investigated. The possible existence of some inhibitor(s) for the modori-phenomenon in the serum fraction was also described.

\section{Materials and methods}

\section{Rainbow Trout}

Four rainbow trouts $(387-402 \mathrm{~g}$ in body weight and $29-30 \mathrm{~cm}$ in body length) cultured in the same pond under the same breeding condition in Shiga Prefectural Samegai Trout Farm were used for the experiments. Two were immediately killed by striking in the head after having been taken from the pond and then one of which was bled as completely as possible from caudal artery by a syringe $(11.8 \mathrm{ml}$ of blood was recovered) and the other was not. Another two were transported to the laboratory in Kyoto alive in a polyethylene bag. Afterwards, the fishes were agitated in shallow water for $30 \mathrm{~min}$ and then killed by striking in the head. Similar to the immediately killed fish, one was bled ( $11.5 \mathrm{~m} /$ of blood was recovered) and the other was used without bleeding. Because almost the same amounts of blood were recovered from both the immediately and strugglingly killed fishes, the death condition seemed to not affect the bleeding significantly. These four rainbow trouts were stored at $4^{\circ} \mathrm{C}$.

\section{Gel Preparation}

A small portion (about $20 \mathrm{~g}$ ) of muscle was excised from each fish at selected time intervals after death. The muscle was minced and ground with $2.5 \% \mathrm{NaCl}$ for $2 \mathrm{~min}$. Salt-ground meat paste was packed in a small glass tube (diameter, $15 \mathrm{~mm}$; height, $15 \mathrm{~mm}$; thickness, $1 \mathrm{~mm}$ ) and then heated at $65^{\circ} \mathrm{C}$ for $2 \mathrm{~h}$. Fairly tough gel was formed once and then gradually degraded during heating. Two hours heating was judged to be appropriate to compare the degree of the modori-phenomenon of rainbow trout in the preliminary experiment. It was impossible to make gels from the immediately killed fishes due to the restriction of facilities.

*1 Laboratory of Fishery Chemistry, Department of Fisheries, Faculty of Agriculture, Kyoto University, Kitashirakawa, Sakyo, Kyoto 606, Japan（豊原治彦，俈々木和夫，木下政人，志水 筧：京都大学㟽学 部).

*2 C. N. Wendakoon: Master thesis of Faculty of Agriculture, Kyoto University, kyoto, 1988, pp. 86-106. 
Evaluation of the Degree of the Modori-phenomenon Sensory evaluation of gel was carried out by an experienced panelist with teeth-cutting and folding tests according to the method of Shimizu et $a l^{\left({ }^{y}\right)}$ The mean score for two test pieces was determined in the teeth-cutting test. The teeth-cutting test was performed by cutting of the test pieces, $15 \mathrm{~mm}$ in diameter and $3 \mathrm{~mm}$ in thickness, by the foreteeth and scoring "toughness" according to 10 points scale (10, extremely tough; 8 , tough; 6 , moderately tough; 4 , fragile; 2 , very fragile; 0 , like mud). The folding test was done by folding the test pieces having the same diameter and thickness as those for the teeth-cutting test neatly in half and evaluating into four grades ( $A$, no crack occurred; B, cracked; C, cracked and separated into two pieces; D, easy to break like mud). The folding test was also examined for about two test pieces.

The breaking strength was measured with Yamaden RE-3305 rheometer equipped with a column type plunger (diameter: $3 \mathrm{~mm}$ ) at the speed of $1 \mathrm{~mm} / \mathrm{sec}$. The average values obtained for two pieces are expressed in the figures and the table.

\section{Measurement of Muscle pH}

A small portion of muscle was homogenized with 10 volumes of distilled water and then the $\mathrm{pH}$ of the homogenate was measured immediately with a $\mathrm{pH}$ meter (Horiba Co. Ltd).

Effect of the Addition of the Serum Fraction Prepared from Rainbow Trout Blood on the ModoriPhenomenon

After coagulating by standing at $4^{\circ} \mathrm{C}$ for $5 \mathrm{~h}$, collected blood was centrifuged at $2,500 \mathrm{rpm}$ for $10 \mathrm{~min}$. The supernatant was used as the serum fraction. To examine the effect of the serum fraction on the modori-phenomenon, the serum fraction prepared from the fish killed while struggling was added to the minced meat of the same fish stored for $24 \mathrm{~h}$ prior to the salt-grinding. Bovine serum albumin (Sigma) dissolved in water to give an equal protein concentration to the serum fraction was added to each gel to adjust the added protein concentration same $(20.7 \mathrm{mg}$ protein equivalent to bovine serum albumin). The amount of the serum fraction added is expressed as the percentage to the minced meat in Table 1 and Fig. 3.

\section{Estimation of the Breakdown of Myosin Heavy Chain}

Gel was homogenized with 10 volumes of dis- tilled water. One hundred microliter of the homogenate was heated in boiling water for $5 \mathrm{~min}$ with $0.1 \mathrm{ml}$ of $100 \mathrm{~mm}$ Tris- $\mathrm{HCl}$ buffer, $\mathrm{pH}$ 6.8 , containing $10 \% \mathrm{SDS}$ and $50 \mathrm{~mm} 2$-mercaptoethanol, and $0.8 \mathrm{~m} /$ of $50 \%$ glycerol to dissolve the homogenate completely. Thirty microgram protein equivalent to bovine serum albumin was applied on the analysis by sodium dodecylsulfate polyacrylamide gel electrophoresis in $10 \%$ gel according to the method of Laemmli. ${ }^{10}$ Because any polymerized high molecular weight product was not recognized in or on the top of the stacking gel, it seemed no problem to compare each lane in the electrophoretic analysis. Staining was carried out with Coomassie Brilliant blue R-250.

\section{Results}

Change in the Modori-Causing Property of Immediately Killed Fish with or without Bleeding

Fig. 1 shows the change of the strength of gels prepared from the immediately killed fishes. Judged from the breaking strength and the sensory score, all gels from the bled fish showed the modori-phenomenon (Fig. 1-a), while those from the non-bled fish did not (Fig. 1-b). It is also noteworthy that the evaluation of the gel strength by the breaking strength and the sensory score coincided well.

In addition, it is of particular interest that the degree of the modori-phenomenon of the gels prepared from the bled fish changed according to the storage period after death as shown in Fig. 1-a. Gel strength determined by the breaking strength was the weakest at $6 \mathrm{~h}$-storage, and then became stronger $9 \mathrm{~h}$-storage, but was getting weak again $24 \mathrm{~h}$-storage. In this case, the changing pattern of the gel strength was well coincided with that of muscle $\mathrm{pH}$ as already suggested by Shimizu and Kaguri. $^{\text {e) }}$

Change in the Modori-Causing Property of Strugglingly Killed Fish with or without Bleeding

Fig. 2 shows the change in the strength of gels prepared from the fishes killed while struggling. Similar to the case of the immediately killed fish, the modori-phenomenon was observed only for gels prepared from the bled fish (Fig. 2-a). It is notworthy that gels prepared from the fish stored for $6 \mathrm{~h}$ became fragile, while fairly tough gels were formed from the fish immediately after death and stored for $3 \mathrm{~h}$. However, different from the case of the fish immediately killed and 


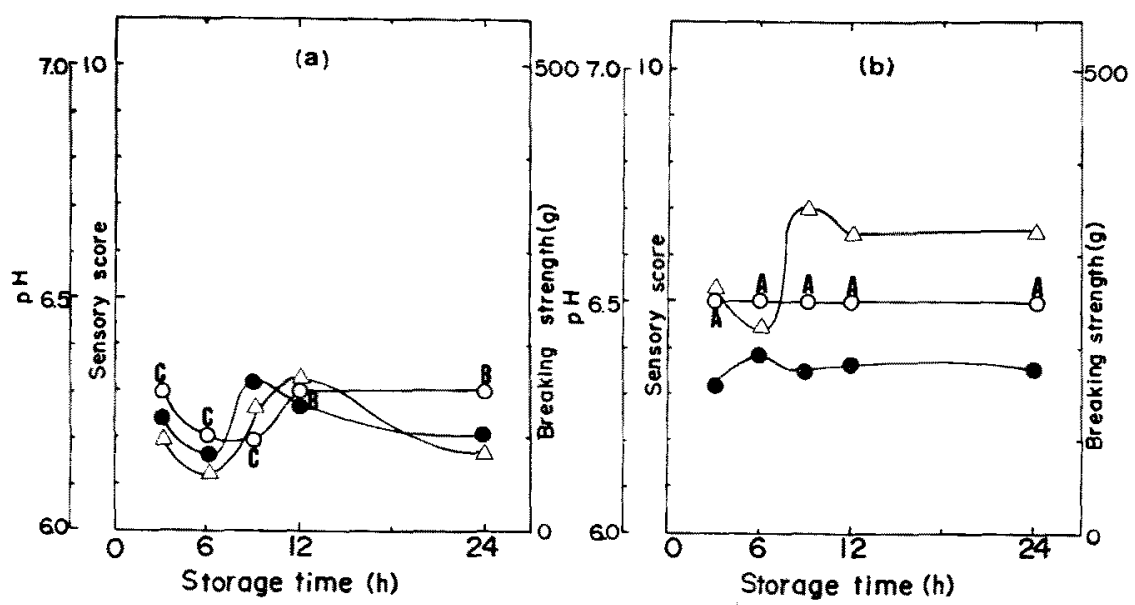

Fig. 1. Change in the modori-causing property of immediately killed rainbow trout with bleeding (a) or without bleeding (b) during $24 \mathrm{~h}$-storage after death at $4^{\circ} \mathrm{C}$. The salt-ground minced meat was heated at $65^{\circ} \mathrm{C}$ for $2 \mathrm{~h}$. Letters in the figure indicate the grade in the folding-test. Details are described in the text. - - breaking strength; $\mathrm{O}-\mathrm{O}$, score in the teeth-cutting test: $\Delta-\triangle$, muscle $\mathrm{pH}$.
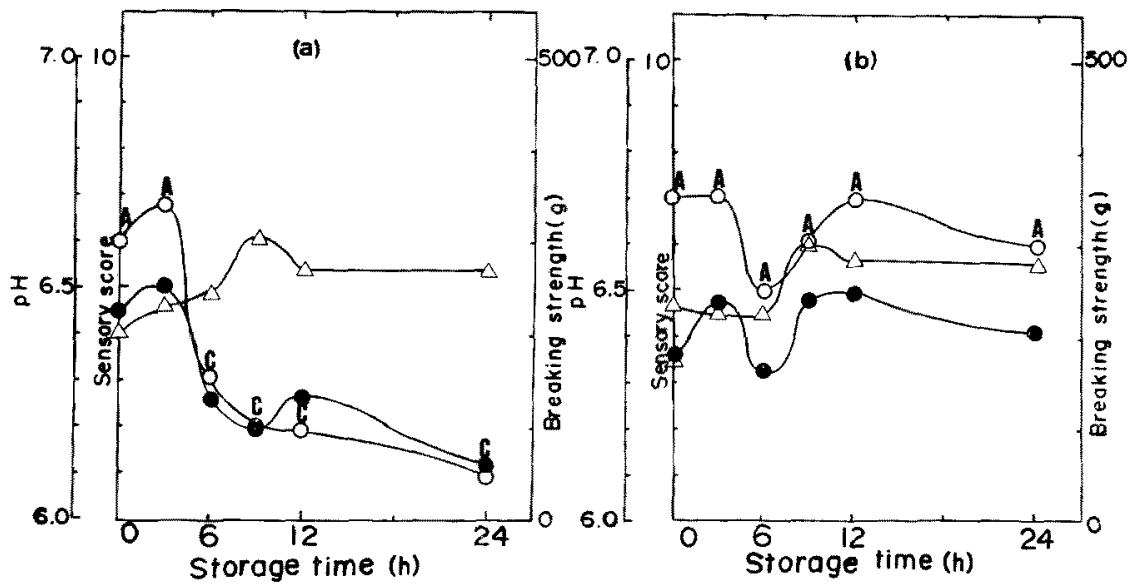

Fig. 2. Change in the modori-causing property of strugglingly killed rainbow trout with bleeding (a) or without bleeding (b) during $24 \mathrm{~h}$ storage after death at $4^{\circ} \mathrm{C}$. Salt-ground minced meat was heated at $65^{\circ} \mathrm{C}$. Letters in the figure indicate the grade in the folding-test. Details are described in the text. - , breaking strength; $\mathrm{O}-\mathrm{O}$, score in the teeth-cutting test; $\triangle-\Delta$, muscle $\mathrm{pH}$.

Table 1. Effect of the rainbow trout serum fraction on the modori phenomenon*1

\begin{tabular}{lrrrr}
\hline \hline Serum concn. $(\%)^{* 2}$ & 0 & 1 & 2.5 & 5 \\
\hline Breaking strength $(\mathrm{g})^{* 3}$ & 76 & 103 & 168 & 223 \\
Sensory score & $2 \mathrm{C}$ & $3 \mathrm{~B}$ & $4 \mathrm{~A}$ & $6 \mathrm{~A}$ \\
\hline
\end{tabular}

*) The serum fraction prepared from the strugglingly killed fish was added to the miced meat of the same fish stored for $24 \mathrm{~h}$ prior the salt-grinding.

*2 Amount of the serum fraction added is expressed as the percentage to the minced meat.

* Degree of the modori-phenomenon was evaluated as described in"Materials and methods". 


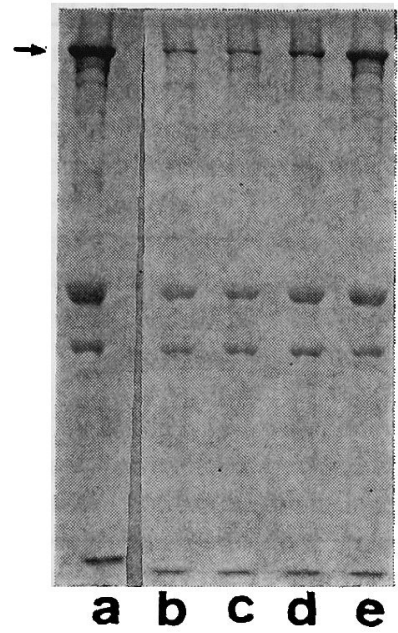

Fig. 3. SDS-PAGE analysis of the breakdown of myosin heavy chain. The serum fraction obtained from strugglingly killed fish was added to the minced meat of the same fish stored for $24 \mathrm{~h}$. Bovine serum albumin dissolved in water to give an equal protein concentration to the serum fraction was added to each gel to adjust the protein concentration same $(20.7 \mathrm{mg}$ protein equivalent to bovine serum albumin). The amount of the serum fraction added is expressed as the percentage to the amount of the minced meat. The arrow indicates the myosin heavy chain band. a, minced meat and 5\% serum without heating; $b$, minced meat and no serum with heating; $c$, minced meat and $1 \%$ serum with heating; d, minced meat and $2.5 \%$ serum with heating; e, minced meat and 5\% serum with heating.

bled (Fig. 1-a), the decrease of the gel strength did not correspond with the change of muscle $\mathrm{pH}$. The strength of gels prepared from the non-bled fish stored for $6 \mathrm{~h}$ became weak, which was not judged as modori-gel, presenting no creack in the folding test (Fig. 2-b).

\section{Effect of the Serum Fraction of the Modori-Phen- omenon}

The results shown in Figs. 1 and 2 suggested the possibility that blood contaminated in non-bled fish meat might suppress the modori-phenomenon. To examine this, effect of the serum fraction on the modori-phenomenon was investigated. As shown in Table 1, the gel strength was recovered markedly by the addition of $5 \%$ of the serum fraction. Moreover, the breakdown of myosin heavy chain, which was supposed to be the cause of the modori-phenomenon, ${ }^{1)}$ was also inhibited by the addition of the serum fraction (Fig. 3). These results suggest the possibility that the serum fraction contained some inhibitor(s) for the modori-phenomenon. The additional possibility that this recovery in the gel strength was due to the gel forming ability of the added serum fraction seems to be eliminated, because the serum fraction itself did not show any gel-forming property at $65^{\circ} \mathrm{C}$ (data not shown).

\section{Discussion}

The results presented in Figs. 1 and 2 suggested that bleeding might promote the modori-phenommenon, because the modori-phenomenon was observed only for the gels prepared from the bled fish irrespective of the death condition. This was further confirmed in the separate experiments performed on the other day and almost similar results were obtained for other fish species including tilapia and crucian carp (data not shown). Therefore, it was speculated that blood contains some inhibitor(s) for the modori-phenomenon. This speculation was confirmed by the experiment shown in Table 1 and Fig. 3. Further purification and characterization of the serum modori-inhibitor(s) are now being pursued.

On the other hand, Shimizu and Kagurios pointed out that the decrease of post-mortem muscle $\mathrm{pH}$ might correspond to the enhancement of the modori-phenomenon using tilapia. However, relation of post-mortem muscle $\mathrm{pH}$ and the degree of modori-phenomenon was not clearly demonstrated in our experiment, because the contradictory effect was observed for the gels prepared from the fish immediately killed and bled (Fig. 1-a) and for those from the fish strugglingly killed and bled (Fig. 2-a). In addition, it is also interesting that the increase of $\mathrm{pH}$ at $9 \mathrm{~h}$ storage muscle was observed for all fishes. However, no explanation is available for this phenomenon at present.

Except for the case of the immediately killed fish without bleeding (Fig. 1-a), the strength of all gels prepared from the fish stored for $6 \mathrm{~h}$ showed the tendency to become weak. The underlying mechanisms, however, still remains poorly understood.

\section{Acknowledgments}

The authors are greatly indebted to Dr. Shozo Fushiki and Mr. Toru Kobayashi of Shiga Prefectural Samegai Trout Farm for their kind gift 
of rainbow trouts. This study was partly supported by a grant from Towa Food Research Foundation.

\section{References}

1) H. Toyohara and Y. Shimizu: Agric. Biol. Chem., 52, 255-257 (1988).

2) H. Toyohara, M. Kinoshita, and Y. Shimizu: J. Food Sci., 55, 259-260 (1990).

3) H. Toyohara, T. Sakata, K. Yamashita, M. Kinoshita, and Y. Shimizu: J. Food Sci., 55, 364-368 (1990).

4) M. Kinoshita, H. Toyohara, and Y. Shimizu: J. Biochem., 107, 587-591 (1990).
5) Y. Shimizu, R. Machida, and S. Takanami: Nippon Suisan Gakkaishi, 47, 95-104 (1981).

6) Y. Shimizu and A. Kaguri: Nippon Suisan Gakkaishi, 52, 1837-1841 (1986).

7) Y. Shimizu, R. Machida, M. Kawasaki, and A. Kaguri: Gen. Rep. of the Studies on Effective Utilization of Abundantly Caught Darkfleshed Fish Species (ed. by Fishery Agency), Fishery Agency, 1982, pp. 53-62.

8) Y. Shimizu and N. C. Wendakoon: J. Sci. Food Agric., in press (1990).

9) Y. Shimizu, A. Nomura, and F. Nishioka: Nippon Suisan Gakkaishi, 52, 2027-2032 (1986).

10) U. K. Laemmli: Nature (London), 227, 680685 (1970).

Nippon Suisan Gakkaishi : Formerly Bull. Japan. Soc. Sci. Fish. 